\title{
Intravenous therapy and EEG monitoring in prolonged seizures
}

\author{
G. PAMPIGLiONE AND A. A. DA COSTA \\ From the Department of Neurophysiology, The Hospital for Sick Children, \\ Great Ormond Street, London
}

SYNOPSIS Attempts were made to control prolonged seizures with rapid intravenous administration of either diazepam or methohexitone in relatively small doses under electroencephalographic (EEG) monitoring. The clinical and EEG features are discussed in relation to 65 episodes which occurred in 51 infants and children. Both clinical and EEG effects may become apparent in half a minute when the drug is administered with this technique and no undesirable side-effects were observed. The return of consciousness was not impaired by the small amounts of these drugs and the cumulative effects were negligible, allowing repeated injections if necessary. This technique avoids the disadvantages of larger doses of drugs given by slow intravenous infusion.

Status epilepticus has been defined arbitrarily as a series of two or more major convulsions without intervening recovery of consciousness or as continuous major convulsions lasting for more than one hour (British Medical Journal, 1972). In the recently published Dictionary of Epilepsy (Gastaut, 1973), status epilepticus has been described as: 'a condition characterised by an epileptic state that is sufficiently prolonged or repeated at sufficiently brief intervals so as to produce an unvarying and enduring epileptic condition'; such tautology emphasizes our ignorance. Several terms such as 'uncontrolled seizure activity', 'acute repetitive seizures', 'partial epileptic state', 'twilight state', 'minor status epilepticus', have appeared in the recent literature to describe practically continuous attacks which may be at variance with major status epilepticus. In infants and young children during such episodes, which may last hours or days, the clinical manifestations are usually even more varied than those of adults and verbal communication cannot be relied upon to assess the severity and the continuity of the 'epileptic state'.

In the present paper the term 'prolonged seizures' indicates any combination of clinical

(Accepted 4 November 1974.) manifestation of the epilepsies lasting 20 or more minutes associated with a variety of continuing discharges as seen in the electroencephalogram (EEG). Prolonged seizures are usually considered to be a medical emergency, requiring urgent treatment. Paraldehyde, diphenylhydantoin,thiopentone, and, more recently, diazepam, are commonly used but in the recommended doses have a considerable soporific effect. This makes it difficult to assess clinically whether the patient's unrousability is due to drug effect or to the continuation of prolonged seizures.

In contrast with the commonly employed slow intravenous infusion of anticonvulsants in the control of prolonged seizures, a different approach has been used in the present study. The drug was given intravenously in a small dose rapidly injected as a bolus under continuous EEG monitoring and, of course, continuing clinical observation.

\section{METHODS}

Over the period 1957-73 episodes of prolonged seizures had occurred in 328 children referred for neurophysiological investigations, whether during or after an episode. In 51 of these ( 37 boys and 14 girls) one or more attempts to control the prolonged seizures were made as described below in the course 371 
27 children between 1 and 6 years, and 9 between 6 and 15 years of age.

The EEGs were taken with uniform techniques using silver-silver chloride electrodes, stuck to the scalp with collodion according to measurements from bony landmarks (Pampiglione, 1956). Whenever possible, a polyelectromyogram (EMG) was also obtained with techniques previously described (Pampiglione, 1966). The EEG apparatus was an Offner-Beckman 8-channel type T. The time constant usually employed was 0.3 seconds, though sometimes increased to one second. The high frequency response was linear within $10 \%$ up to $70 \mathrm{~Hz}$. The sensitivity was usually of $10 \mu \mathrm{V}$ per mm pen deflection and the contact resistance with the scalp was of the order of $5 \mathrm{k} \Omega$. A preliminary EEG was taken at the patient's bedside in the ward or in the intensive care unit, and it was at this stage in the course of prolonged seizures that the selected drug (either diazepam or

TABLE 1

MAIN CLINICAL FEATURES

\begin{tabular}{lr}
\hline Clinical features & Episode \\
\hline Unilateral tonic or clonic phenomena & 11 \\
Generalized tonic/clonic seizures & 1 \\
Ataxia, grogginess, minor twitching, limited contact & 13 \\
Myoclonic phenomena with variable distribution & 23 \\
Stupor or coma with nearly continuous EEG discharges & 4 \\
Mixed type of seizures & 13 \\
\hline Total episodes & 65 \\
\hline
\end{tabular}

methohexitone) was injected rapidly as a bolus. An appropriate resuscitation trolley was kept at hand, but on no occasion did it become necessary either to assist the patient's respiration or even to use an airway. Diazepam was given in doses of 0.5 to $2.0 \mathrm{mg}$, while the dose for methohexitone was between 3 and $10 \mathrm{mg}$ (1:100 solution). The syringe was loaded with two to three times the selected dose so that the injection could be repeated if desirable without removing the needle. The most effective bolus injection was completed within three to five seconds, either directly in a superficial vein or sometimes through an intravenous line which was then promptly flushed. A single drug was administered in the course of all the 65 episodes whether in one or repeated doses. Close clinical observations as well as EEG monitoring, which had started before the injection, continued throughout. Particular notice was taken of the events some 15 to 40 seconds after the end of the injection, as during this phase the main clinical and
EEG changes are expected. If clinical and/or EEG changes were of doubtful interpretation a second of dose was given one to five minutes after the first. If methohexitone or diazepam had failed to control 0 the prolonged seizures further drugs in the more generally recommended doses were administered more slowly (including also thiopentone, phenytoin, paraldehyde, phenobarbitone, nitrous oxide) usually with little if any benefit.

In the 51 children (65 episodes), 39 were studied during a single episode, 10 during two episodes, and two during three episodes. Further records, whenever necessary, were taken a few hours later or on the $\vec{\Phi}$ next day.

\section{RESULTS}

The main clinical features of the prolonged $\vec{\omega}$ seizures are listed in Table 1, but there was some degree of variability in the severity of the clinical phenomena in each baby or child. During 13 epi- $\dot{\infty}_{\infty}$ sodes the seizures were of mixed type throughout. $\stackrel{\oplus}{+}$ Moreover, in 12 children who had been studied $\omega_{y}$ during multiple episodes, the clinical features $\vec{\circ}$ were not identical in each episode. There was a greater variability of clinical features in the first $\vec{D}$ year of life than in the older children.

TABLE 2

PREDOMINANT EEG FEATURES BEFORE DRUG ADMINISTRATION*

\begin{tabular}{|c|c|}
\hline EEG features & Episode \\
\hline $\begin{array}{l}\text { Bilateral multifocal spikes and sharp waves } \\
\text { Lateralized spikes and sharp waves } \\
\text { Irregular slow waves mixed with few spikes } \\
1-2 \frac{1}{2} \text { per second wave-and-spike (or polyspikes) com- } \\
\text { plexes }\end{array}$ & $\begin{array}{r}46 \\
28 \\
34 \\
5\end{array}$ \\
\hline
\end{tabular}

* The overlap in numbers is due to the frequent variability of the predominant features during each prolonged episode.

The main EEG features also varied to some extent during each episode, and in Table 2 someo of the more obvious aspects are listed, though each group of patterns could either coexist or을 alternate with other patterns in the course of each prolonged episode. The effects of diazepam? and methohexitone are listed in Tables 3 and 4. 0

When the clinical seizures were interrupted $\omega$ and the discharges in the EEG disappeared after? the rapid injection of the drug, such effects? 
usually became obvious in less than half a minute from the end of the injection. However, in five cases such effects appeared less promptly, being delayed for a further 30 to 90 seconds. In these cases, it was presumed that the drug did not reach as a bolus the area of the brain responsible for the seizures, possibly because of vascular occlusion as in multiple embolism.

When for various reasons the intravenous injection could not be administered as rapidly as desirable, both clinical and EEG effects were much less obvious and often uncertain, probably due to the lower concentration of the drug in the blood. A rapid amelioration in the EEG was never seen without a concomitant clinical improvement, but in 24 children a transitory arrest of the motor phenomena occurred within half a minute without any EEG improvement. In all these patients the clinical manifestations reappeared some three to five minutes later, presumably when the effect of the drug had vanished.

The following two cases illustrate some of the advantages and limitations of our present approach to the control of prolonged seizures.
CASE 1

After a normal pregnancy and delivery this boy was noted to be cyanotic. A diagnosis of total transposition of the great arteries was made and a Rashkind procedure was carried out at this hospital on the ninth day post partum. At the age of 2 years and 3 months a preoperative EEG showed no abnormalities (Fig. 1A) and on 30 September 1969 the patient had a Mustard operation under cardiopulmonary bypass. The immediate postoperative period was satisfactory with full recovery of consciousness, but on 4 October 1969 he had an acute episode in which he became cyanosed and stared vacantly with his eyes deviated to the right for several hours without obvious twitching. He remained out of touch with his eyes open and his left foot in plantar extension with firmly flexed toes. On occasions this boy could be made to assume catatonic postures of his limbs, although there was usually some leftsided weakness. Respiration was poor and the child was intubated and attached to an Engstrom ventilator. An emergency EEG was carried out, showing marked excess of irregular slow activity over the left hemisphere reaching 100 to $400 \mu \mathrm{V}$, while over the right hemisphere continuous irregular discharges reaching $1 \mathrm{mV}$ were seen, maximal in the right

A

C

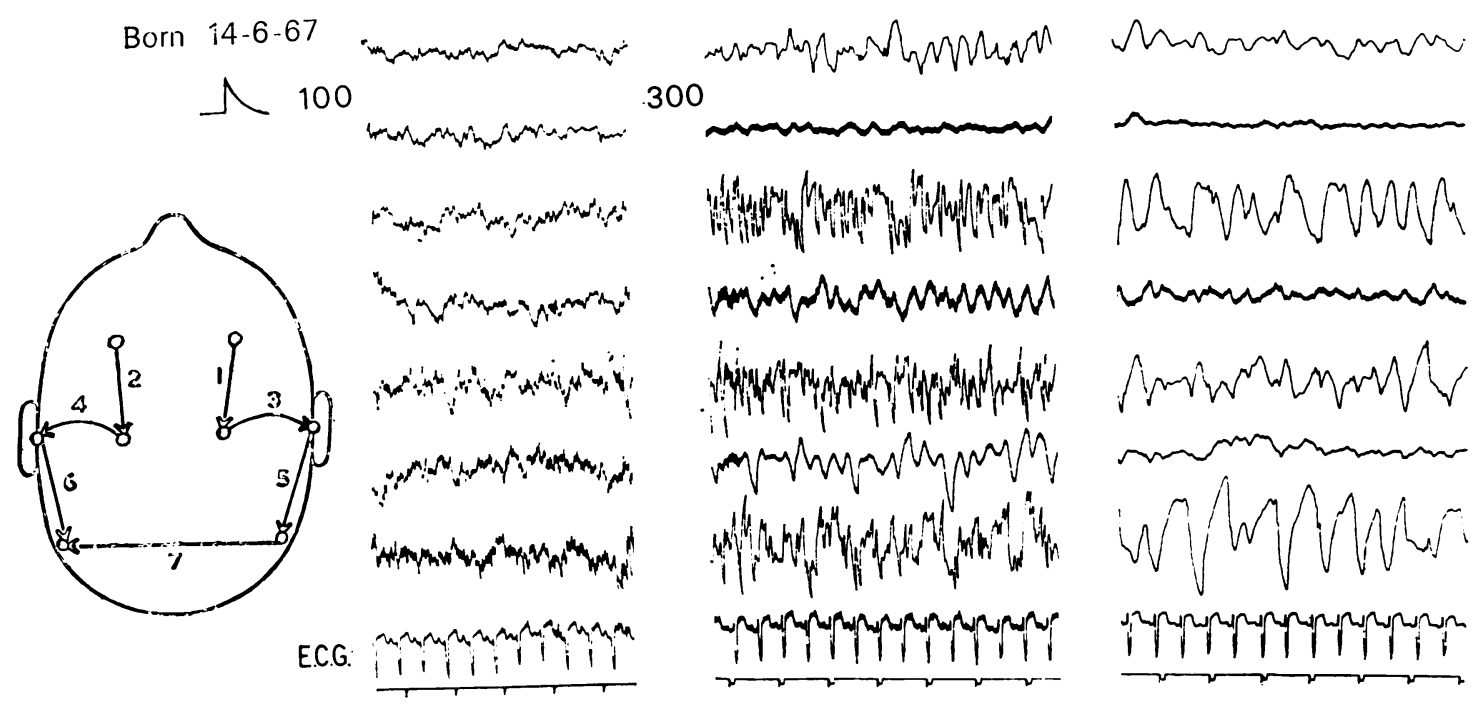

FIG. 1 Case 1. EEG in the first seven channels, ECG in the eighth channel and time marker in seconds. A: 29 September 1969. The day before operation (calibration $100 \mu \mathrm{V}$ per cm pen deflection). B: 4 October 1969. Four days after operation during neurological complications and prolonged seizure (calibration $300 \mu V$ per cm pen deflection). C: 4 October 1969. One minute after intravenous administration of diazepam $0.5 \mathrm{mg}$, which interrupted the prolonged seizure. 

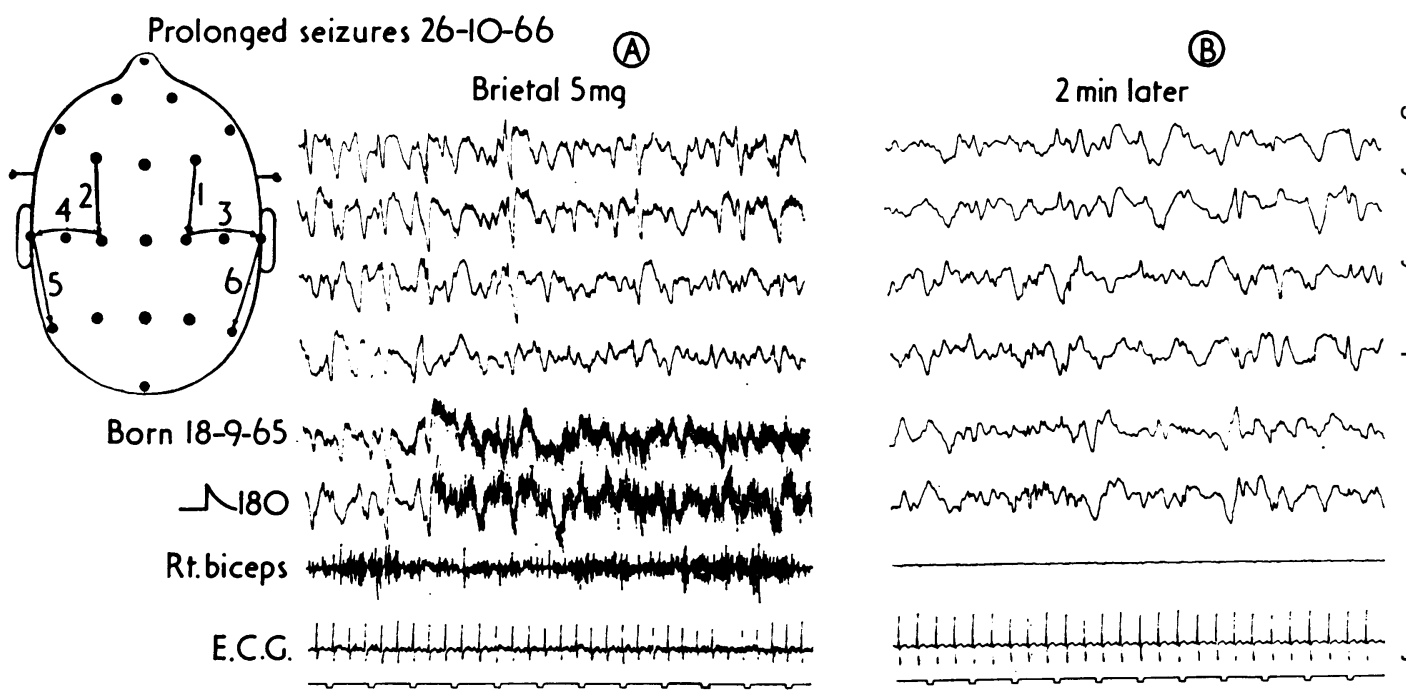

FIG. 2 Case 2. EEG in the first six channels, surface EMG in seventh channel, ECG in eighth channel, time, marker in seconds and calibration of $180 \mu \mathrm{V}$ per cm pen deflection. A: during prolonged seizure and at the time of intravenous administration of methohexitone $5 \mathrm{mg}$. B: Two minutes later when this boy had stopped twitchingu

temporal and posterior temporal regions (Fig. 1B), unchanged by various stimuli including endotracheal suction. A small dose of diazepam was given intravenously as a bolus of $0.5 \mathrm{mg}$ and this was followed in about one minute by a disappearance of the discharges over the right hemisphere (Fig. 1C) and recovery of consciousness. The child gradually improved but a left homonymous hemianopia and some weakness of the left hand persisted for several weeks. The patient was discharged on 25 October 1969 and six months later there was no neurological abnormality and cardiocirculatory function was satisfactory. The whole episode was considered to be due to embolic phenomena, without long-lasting sequelae.

\section{CASE 2}

After a normal pregnancy and delivery, this boy appeared to develop well but he had a seizure at the age of 1 month and another at the age of 4 months. After the age of 6 months his progress stopped and seizures became more frequent. He was admitted to hospital at the age of 8 months for investigations: an EEG showed an excess of slow activity without focal or paroxysmal features and a lumbar pneumoencephalogram showed some degree of cerebral atrophy, the left hemisphere being more affected than the right. After his discharge and in spite of anticonvulsants his seizures became much more frequent and severe. When readmitted at 13 months, he was grossly retarded, spastic, and his seizures laske $\overrightarrow{\$}$ hours with practically continuous minimal jerkings his fingers and toes, occasionally involving also tis. face and limbs. This state was occasionally intere rupted by gross jerks involving both arms, legs, ลี่ the trunk. The EEG now showed a severe generaP ized abnormality with not only a marked increase if slow activity but also very frequent multifocal spike and sharp waves involving both hemispheres Despite primidone $(125 \mathrm{mg} \times 3)$, phenytoin $(30 \mathrm{mg}$ $\times 3)$, phenobarbitone $(60 \mathrm{mg} \times 4)$, and paraldehyde as required, this child did not improve and contacf with him was variable during the waking statewhile during behavioural sleep the jerks disappeared In the EEG there was again a gross excess of slow. activity and multifocal discharges and an EMG fron the right biceps showed groups of muscle action potentials and occasional single spikes associate with the twitching episodes (Fig. 2A). These somed times alternated with more prolonged variable tonio contractions, during which this boy became severely cyanotic. A total of $5 \mathrm{mg}$ methohexitone was given in two rapidly injected doses of 2 and $3 \mathrm{mg}$. The child stopped twitching while the discharges in the. EEG were greatly reduced (Fig. 2B). Recording cons tinued for 20 minutes after the control of seizureș and twitching did not recur. This boy when last seep at the age of $8 \frac{1}{2}$ years was still retarded and spastic. but more alert with occasional episodes of jerking, i spite of anticonvulsants, folic acid, and prednisolone 
TABLE 3

EFFECT OF INTRAVENOUS DIAZEPAM (48)

\begin{tabular}{lcccc}
\hline $\begin{array}{l}\text { Type of } \\
\text { seizure }\end{array}$ & $\begin{array}{c}\text { EEG and } \\
\text { clinical } \\
\text { improvement }\end{array}$ & $\begin{array}{c}\text { Clinical } \\
\text { improvement } \\
\text { only }\end{array}$ & $\begin{array}{c}\text { EEG } \\
\text { improvement } \\
\text { only }\end{array}$ & $\begin{array}{c}\text { No effect } \\
\text { or uncertain } \\
\text { effect }\end{array}$ \\
\hline Generalized & 1 & - & - & - \\
Focal & 2 & 5 & - & 1 \\
$\begin{array}{l}\text { Myoclonic } \\
\text { Minor }\end{array}$ & 4 & 6 & - & 7 \\
$\begin{array}{l}\text { Stupor/coma } \\
\text { Mixed }\end{array}$ & 4 & 2 & - & 3 \\
\hline Total & 2 & - & - & 3 \\
\hline
\end{tabular}

TABLE 4

EFFECT OF INTRAVENOUS METHOHEXITONE (17)

\begin{tabular}{lcccc}
\hline $\begin{array}{l}\text { Type of } \\
\text { seizure }\end{array}$ & $\begin{array}{c}\text { EEG and } \\
\text { clinical } \\
\text { improvement }\end{array}$ & $\begin{array}{c}\text { Clinical } \\
\text { improvement } \\
\text { only }\end{array}$ & $\begin{array}{c}\text { EEG } \\
\text { improvement } \\
\text { only }\end{array}$ & $\begin{array}{c}\text { No effect } \\
\text { or uncertain } \\
\text { effect }\end{array}$ \\
\hline $\begin{array}{l}\text { Generalized } \\
\text { Focal }\end{array}$ & - & - & - & - \\
$\begin{array}{l}\text { Myoclonic } \\
\text { Minor }\end{array}$ & 2 & - & - & - \\
$\begin{array}{l}\text { Stupor/coma } \\
\text { Mixed }\end{array}$ & 1 & 1 & - & - \\
\hline Total & 1 & - & - & - \\
\hline
\end{tabular}

Both methohexitone and diazepam in small doses, given intravenously as a bolus, have a short-lived effect. In some patients both clinical seizures and EEG discharges stopped altogether, while in others the beneficial effect would last only three to five minutes. In these cases a longer acting related drug was successfully added for longer term management-for instance, phenobarbitone if methohexitone had achieved transitory EEG and clinical control, or nitrazepam if diazepam had a similarly transitory effect.

\section{DISCUSSION}

A large amount of literature has accumulated on the use of anticonvulsant drugs, particularly by slow intravenous infusion in an attempt to interrupt prolonged seizures. In infants and children several authors have emphasized the efficacy of diazepam, including Gordon (1966), Calderon-Gonzales and Mireles-Gonzales (1968), Carter and Gold (1968), McMorris and Mac-
William (1968), and Aicardi and Chevrie (1970).

In an emergency situation where the most important aim is to achieve the suppression of convulsions as rapidly as possible, it is not essential to set up EEG monitoring. However, in a well-equipped hospital where there is an EEG department with experience of the intensive care situation, there are some definite advantages in a combined study of prolonged seizures to assess the efficacy of therapeutic attempts under EEG monitoring.

In children, Lombroso (1966) found that partial seizures were common but Aicardi and Chevrie (1970) thought that generalized convulsions were the most common. Our material shows that twitching or jerking often with variable distribution were common in most age groups. However, in contrast with Lombroso (1966), we deliberately excluded the 'infantile spasms' from our material because in this syndrome each attack, though repeated, is brief and in between such attacks there are usually no continuing seizures or loss of contact.

Over the years we have used several drugs under EEG monitoring during attempts to control prolonged seizures in infants and children. With the introduction of newer, more effective, and safer drugs, the choice is now between the benzodiazepines (in particular diazepam) and short-acting barbiturates (thiopentone and methohexitone). Several authors consider intravenous paraldehyde as the best drug (Rowan and Scott, 1970; Oxbury and Whitty, 1971) primarily in adults, but intramuscular administration is preferred in children.

Diazepam is known to be very useful since the early work by Naquet et al. (1965) and in the literature the recommended doses are from $5 \mathrm{mg}$ to over $100 \mathrm{mg}$ as a slow infusion. In our patients, when a small dose of diazepam was sufficient to control the attacks and stop the discharges in the EEG, there was often a slight increase in fast activity, particularly over the anterior half of the two hemispheres. The 'burst-suppression phenomena' reported by Bell (1970) in the EEG of three of his patients never occurred in our studies and may have been due to the larger doses he employed. We did not meet the other complications attributed to diazepam in the literature, such as hypotension and respiratory depression (mentioned by many authors), cardiac arrest 
(Prensky et al., 1967), hypothermia (Irvine, 1966), abnormal liver function (Parsonage and Norris, 1967), and tonic status epilepticus (Prior et al., 1972).

Methohexitone sodium is an ultrashort-acting barbiturate often used as a rapid anaesthetic agent. This drug has been said to facilitate convulsions in some cases. This, however, has not been our experience, not only in this series of cases, but also in other groups of patients (Pampiglione, 1965). With the small doses employed, behavioural sleep was not induced in the majority of cases. If, however, methohexitone is injected in larger doses, for example $50 \mathrm{mg}$ and pushed as a bolus, sleep is induced promptly: in some patients at this stage there may be a rapid increase in spikes in the EEG without clinical seizures. This phenomenon may be induced equally well by thiopentone in equivalent doses.

The mechanism of action and specific effects of these drugs on the central nervous system are not yet fully understood, in spite of the large amount of literature on the subject. In a given case of prolonged seizures it is not possible either on clinical or EEG grounds to predict whether diazepam or methohexitone will be the more effective and it seems probable that these two drugs act upon different neural mechanisms. In the 12 patients who had two or three separate episodes it was found that if diazepam had been of uncertain effect during the first episode methohexitone could be effective during the next. It may be advantageous to begin with methohexitone, which we know is very rapidly metabolized in a matter of three to five minutes without cumulative effects. If this is ineffective (either one or two injections) then it is worth while attempting to control the attacks with diazepam, as described above. In our experience, if these small doses rapidly given were not effective, much larger doses given more slowly were also ineffective.

In some of the patients with a gross asymmetry between the activities of the two hemispheres and gross lateralized discharges in the EEG during a prolonged seizure we have noticed that the response to either drug instead of appearing within half a minute, may occur more slowly-namely, over one minute or even nearly two minutes (see case 1). Cerebral arterial or venous obstruction may be the cause of such delay as it occurred in three children who werह known to have suffered from multiple embola some hours before the beginning of the prolongee seizures. Both diazepam and methohexiton induce fast activity in the EEG if given in relas tively small doses in normal control subjectso This phenomenon, however, does not usually. appear in an area of the cortex which may have been extensively damaged (Pampiglione, 1965). $\frac{\text { ? }}{\circ}$

Rapidly injected small doses of either diazepanf or methohexitone are as effective as larger doses $\overline{\bar{p}}$ and certainly safer. This is probably due to th method of administration which provides sudden availability of the drug at tissue level with a fairly high though short-lived concentration capable of modifying abruptly cellular metabol $\overrightarrow{\vec{\omega}}$ ism in at least some areas of the brain. When instead, a slow intravenous infusion is employe the results are difficult to evaluate, as it is pos sible that over a period of hours or days the pros longed seizures may stop for unknown reasons perhaps independently of the selected therapy Moreover when a patient is treated with poly? pharmacological enthusiasm there may कुeaccumulation of toxic effects which may intero fere with the control of seizures. Levy a pex Fenichel (1965) have even suggested that excis sive anticonvulsant medication may precipitater status epilepticus. We still know too little aboug normal and abnormal mechanisms underlying cerebral function to speculate further, but the practical success of our approach is sufficientl品 encouraging to be tried out on a larger scale? whether in children or in adults.

The support of the Epilepsy Research Fund is gratefull acknowledged and we wish to thank our colleagues as. well as the EEG technicians in this hospital for their kin help.

\section{REFERENCES}

Aicardi, J., and Chevrie, J. J. (1970). Convulsive statu§ epilepticus in infants and children. A study of 239 cases? Epilepsia (Amst.), 11, 187-197.

Bell, D. S. (1970). The effect of diazepam on the EEG of status epilepticus. Journal of Neurology, Neurosurgery, and Psychiatry, 33, 231-237.

British Medical Journal (1972). Leading article. Statusu epilepticus, 1, 460-461.

Calderon-Gonzales, R., and Mireles-Gonzales, A. (1968) Management of prolonged motor seizure activity ip children. Journal of the American Medical Association, 204 544-546.

Carter, S., and Gold, A. P. (1969). The critically ill child. management of status epilepticus. Pediatrics, 44, 732-733 
Gastaut, H. (1973). Dictionary of Epilepsy (Part I: Definitions). WHO: Geneva.

Gordon, N. S. (1966). Treatment of status epilepticus with diazepam. Developmental Medicine and Child Neurology, 8, 668-672.

Irvine, R. E. (1966). Hypothermia due to diazepam. British Medical Journal, 2, 1007.

Levy, L. L., and Fenichel, G. M. (1965). Diphenylhydantoin activated seizures. Neurology (Minneap.), 15, 715-722.

Lombroso, C. T. (1966). Treatment of status epilepticus with diazepam. Neurology (Minneap.), 16, 629-634.

McMorris, S., and McWilliam, P. K. A. (1969). Status epilepticus in infants and young children treated with parenteral diazepam. Archives of Disease in Childhood, 44, 604-611.

Naquet, R., Soulayrol, R., Dolce, G., Tassinari, C. A., Broughton, R., and Loeb, H. (1965). First attempt at treatment of experimental status epilepticus in animals and spontaneous status epilepticus in man with diazepam (Valium). (Abstract.) Electroencephalography and Clinical Neurophysiology, 18, 427.

Oxbury, J. M., and Whitty, G. W. M. (1971). Status epilepticus in adults: causes and consequences. Brain, 94, 733-744.

Pampiglione, G. (1956). Some anatomical considerations upon electrode placement in routine E.E.G. Proceedings of the Electrophysiological Technologists Association (EPTA) 7, 20-30.

Pampiglione, G. (1965). Very short acting barbiturate (Methohexital) in the detection of cortical lesions. (Abstract.) Electroencephalography and Clinical Neurophysiology, 19, 314.

Pampiglione, G. (1966). Normal and abnormal coordination of movements: a polymyographic approach. Journal of the Neurological Sciences, 3, 525-538.

Parsonage, M. J., and Norris, J. W. (1967). Use of diazepam in treatment of severe convulsive status epilepticus. British Medical Journal, 3, 85-88.

Prensky, A. L., Raff, M. C., Moore, M. J., and Schwab, R. S. (1967). Intravenous diazepam in the treatment of prolonged seizure activity. New England Journal of Medicine, 276, 779-784.

Prior, P. F., MacLaine, G. N., Scott, D. F., and Laurance, B. M. (1972). Tonic status epilepticus precipitated by intravenous diazepam in a child with petit mal status. Epilepsia (Amst.), 13, 467-472.

Rowan, A. J., and Scott, D. F. (1970). Major status epilepticus. A series of 42 patients. Acta Neurologica Scandinavica, 46, 573-584. 